\title{
Molecular Analysis of Cystinosis: Probable Irish Origin of the Most Common French Canadian Mutation
}

\author{
Jean McGowan-Jordan ${ }^{1}$, Karen Stoddard ${ }^{1}$, Luba Podolsky ${ }^{1}$, Elaine Orrbine ${ }^{3}$, \\ Peter McLaine ${ }^{2,3}$, Margaret Town ${ }^{4}$, Paul Goodyer ${ }^{5}$, Alex MacKenzie ${ }^{1}$ and Hans Heick ${ }^{6}$ \\ Departments of ${ }^{1}$ Genetics and ${ }^{2}$ Pediatrics, Children's Hospital of Eastern Ontario, Ottawa \\ ${ }^{3}$ Canadian Pediatric Kidney Disease Research Centre, Ottawa \\ ${ }^{4}$ Nephrourology Unit, Institute of Child Health, London, UK \\ ${ }^{5}$ Division of Pediatric Nephrology, Montreal Children's Hospital, Montreal \\ ${ }^{6}$ Department of Biochemistry, University of Ottawa, Canada
}

\begin{abstract}
Infantile nephropathic cystinosis, an autosomal recessive disease characterized by a lysosomal accumulation of cystine, presents as failure to thrive, rickets and proximal renal tubular acidosis. The cystinosis gene, $C T N S$, which maps to chromosome 17p13, encodes a predicted $55 \mathrm{kDa}$ protein with characteristics of a lysosomal membrane protein. We have conducted extensive linkage analysis in a French Canadian cystinosis cohort identifying a founding haplotype present in approximately half $(21 / 40)$ of the chromosomes studied. Subsequent mutational analysis, in addition to identifying two novel mutations, has unexpectedly revealed a mutation which has been previously found in Irish (but not French) cystinotic families on these 21 French Canadian chromosomes. Haplotype analysis of two Irish families with this mutation supports the hypothesis that Celtic chromosomes represent an extensive portion of cystinosis chromosomes in French Canada. Our analysis underlines the genetic heterogeneity of the French Canadian population, reflecting a frequently unrecognized contribution from non-Gallic sources including the Irish.
\end{abstract}

Keywords: cystinosis; CTNS; French Canadian; mutation; founder

\section{Introduction}

Cystinosis is an autosomal recessive condition characterized by impaired cystine transport out of lysosomes resulting in elevated intracellular cystine levels. In vitro analysis reveals that following cystine loading, leukocyte lysosomes of cystinosis patients display only a

Correspondence: Dr A MacKenzie, Solange Gauthier Karsh Molecular Genetics Research Laboratory, Children's Hospital of Eastern Ontario, 401 Smyth Rd, Ottawa, Ont. K1H 8L1, Canada. Tel: (613) 738 2772; Fax: (613) 738 4833; E-mail: alex@mgcheo.med.uottawa.ca

Received 21 January 1999; revised 3 March 1999; accepted 17 March 1999 negligible egress of cystine, whilst those of heterozygous cystinosis carriers reveal cystine egress of only half the normal maximal velocity., ${ }^{1,2}$ In cystinosis, many tissues accumulate cystine leading to a failure to thrive, impaired renal function, ocular damage and hypothyroidism. By 10 years of age, the majority of cystinosis patients have end-stage renal disease unless cysteamine therapy is introduced at an early stage. ${ }^{3}$

Fine mapping of the cystinosis gene at $17 \mathrm{p} 13^{4,5}$ was an essential precursor to the cloning of a candidate gene, CTNS, by Town et al. ${ }^{6}$ The gene itself is organized into 12 exons spanning $23 \mathrm{~kb}$ of genomic DNA. The predicted protein is 364 amino acids in length and is 


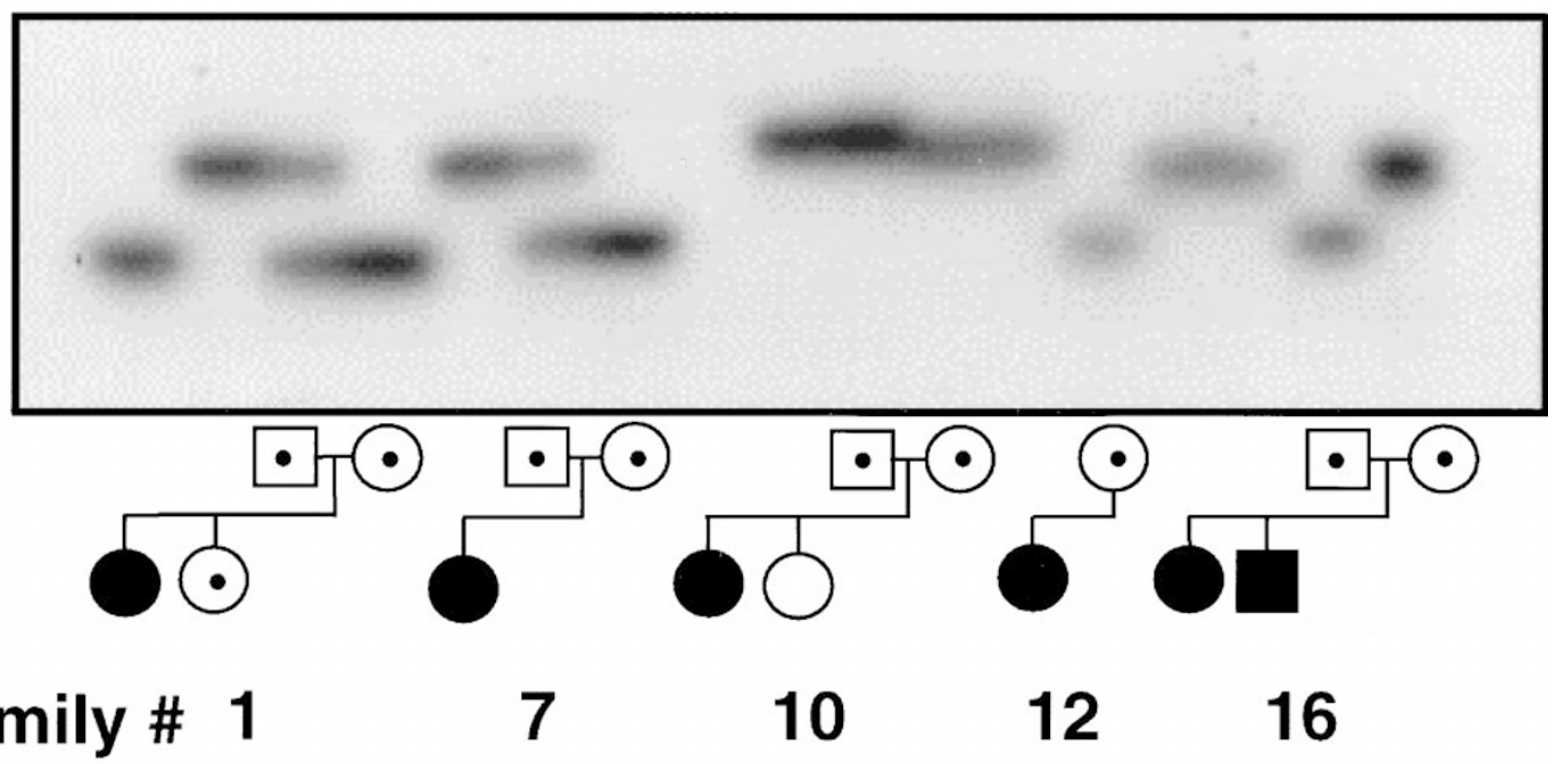

\section{Family \# 1}

B

\section{Family 1}

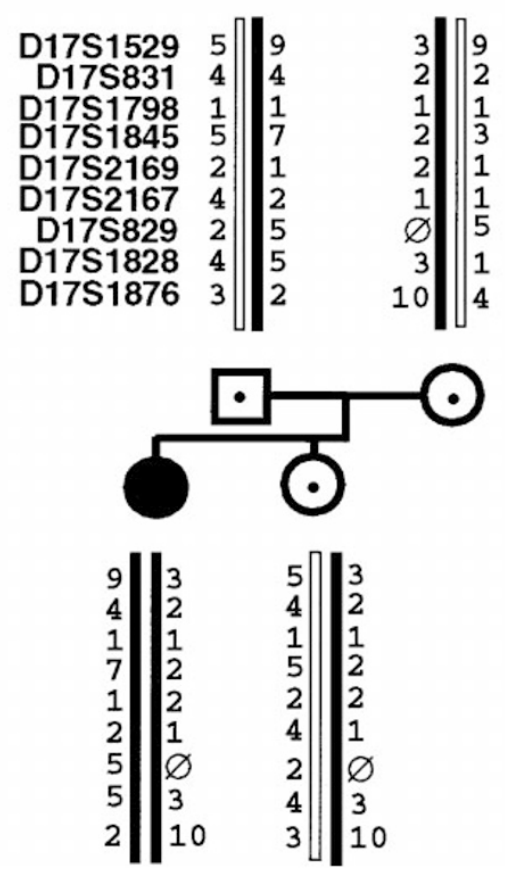

Figure 1 Detection of the deletion incorporating D17S829. A Analysis of D17S829 in cystinosis families by electrophoresis of radiolabelled amplification products and autoradiography. The proband in family 10 (lane 8) was homozygous for the deletion which includes D17S829. Haplotype analysis in other families shows that the probands are compound heterozygotes, with one allele carrying the deletion and the other allele harbouring a second CTNS mutation. Family 1 (lanes 1-4): the unaffected sibling appears to lack a maternal allele. Families 7 (lanes 5-7) and 12 (lanes 12 and 13): the probands have inherited the deletion on the maternal chromosome. Family 16 (lanes 14-17): the probands have inherited the deletion on the paternal chromosome. B Haplotypes of the members of family 1 indicate that there is a deletion on one maternal chromosome $(\phi)$, which the proband has inherited along with an affected paternal chromosome carrying the W138X mutation. 

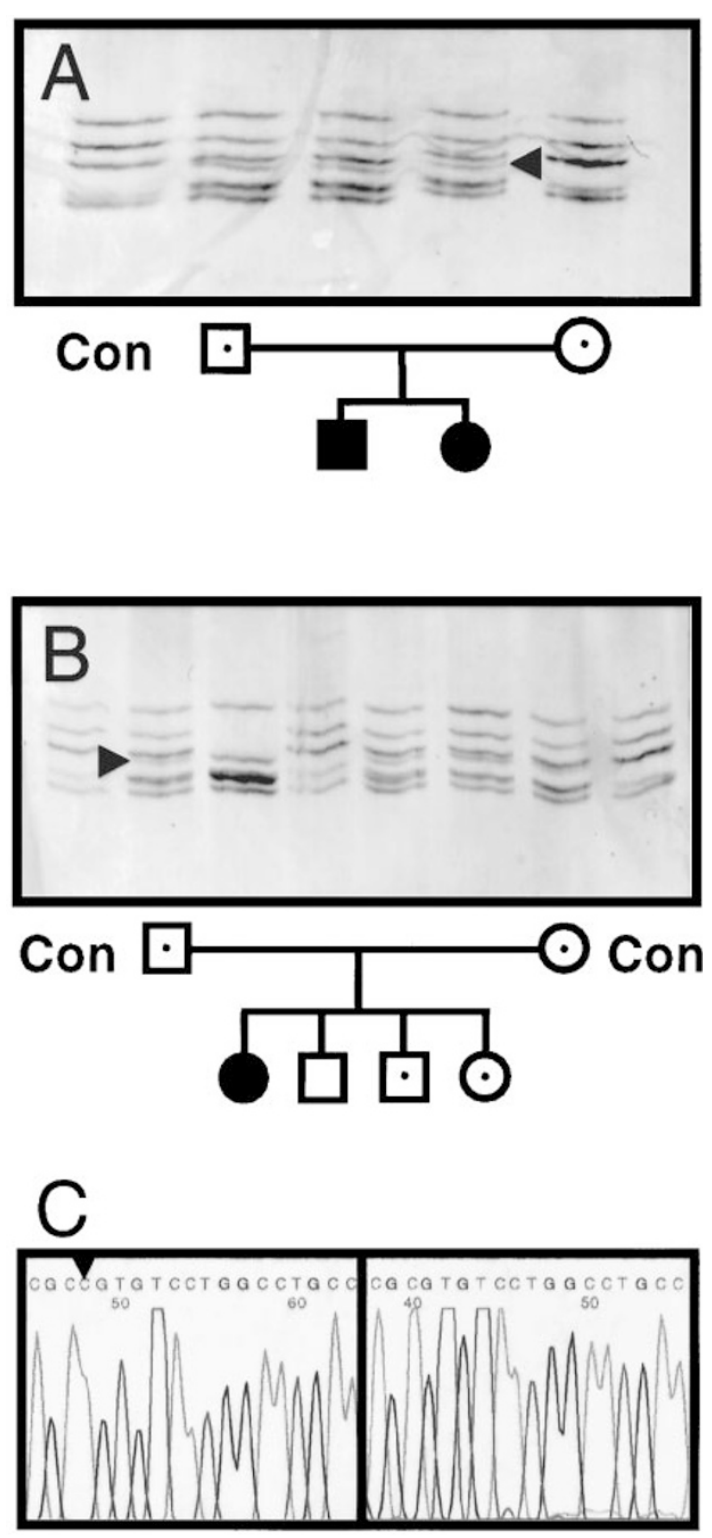

\section{nt1035(insC) Normal}

Figure 2 Detection of small mutations in exon 10 of CTNS by SSCP and sequence analysis. 'Con' indicates control DNA. A SSCP of exon 10 in family 11. An exon 10 mutation causes a bandshift (indicated by arrowheads). The probands are compound heterozygotes, having inherited the exon 10 mutation from their father and the exon 7 mutation (W1328X) from their mother. B SSCP of exon 10 in family 4. The proband is homozygous for the exon 10 mutation, having inherited the mutation from both the mother and father who appear heterozygous. One brother is unaffected whilst the remaining siblings are carriers. C Identification of nt1035(insC) as the exon 10 mutation by sequencing. Partial sequence of exon 10, showing the insertion of a $C$ after base 1035 of the CTNS gene, which results in a frameshift and a premature stop at codon 295. The proband (left) of family 1 appears homozygous for the nt1035(insC) mutation, whilst the mother (right), who carries a deletion of exons 3-10 of CTNS, appears normal. thought to have seven transmembrane domains as well as a motif which is characteristic of lysosomal transport molecules. Thus, CTNS encodes a product which might be expected to export cystine from lysosomes. A number of pathogenic CTNS mutations have been identified: a deletion spanning most of the gene incorporating the microsatellite repeat marker D17S829 at 17p13, and additionally 11 small mutations which were identified in 17 patients. A large study of CTNS mutations in 108 American cystinosis patients ${ }^{7}$ found that $44 \%$ were homozygous for the deletion encompassing exons 3 to 10 of CTNS. Whilst this deletion was found only in patients of British, German and Icelandic origin, additionally 18 mutations were described in people from a variety of ethnic origins.

The incidence of cystinosis in North America is estimated to be 1 per 150000-200000 live births, indicating a carrier frequency of approximately 1 per 400 in the general population, although higher carrier frequencies have been reported in the Bretons ${ }^{3}$ and in French Canadians. ${ }^{8}$ A survey of Canadian pediatric nephrology centres found that 32 of 51 patients with infantile cystinosis were from Quebec and, of these, the significant majority were French Canadians. ${ }^{9}$ The high gene frequency (1/39) which has been reported in French Canadians, ${ }^{8}$ is consistent with a founder effect for the cystinosis gene, due to a small number of carrier individuals who were present in the founding population of Quebec, as has been described for other diseases in this same population. ${ }^{10,11}$ We have undertaken the current study in an effort to identify CTNS mutations in the French Canadian population, and to determine if cystinosis in French Canada is subject to a founder effect.

\section{Subjects and Methods}

\section{Subjects}

Under the auspices of the Canadian Pediatric Kidney Disease Research Centre (CPKDRC), located at the Children's Hospital of Eastern Ontario Research Institute in Ottawa, ${ }^{12}$ 67 blood samples were obtained from 20 cystinosis families from whom informed consent regarding participation in the study had been obtained. The diagnosis of cystinosis in the various kindreds had been established by clinical presentation and the presence of elevated cystine levels in leukocytes. ${ }^{1,2}$

\section{Haplotype Analysis}

Haplotypes of individuals, including the two Irish patients from the Town et al study, ${ }^{6}$ were determined by amplification of microsatellite repeat markers. Primers for D17S1529, D17S831, D17S1845, D17S829, D17S1828, and D17S1876, D17S2167 and D17S2169 were as described. ${ }^{5,13}$ Following end-labelling of one primer from each set with $\gamma^{32} \mathrm{P}$-ATP, 
Table 1 Frequency and description of CTNS mutations in French Canadians

\begin{tabular}{|c|c|c|c|c|c|c|}
\hline $\begin{array}{l}\text { Affected } \\
\text { Exon }(s)\end{array}$ & $\begin{array}{l}\text { Affected } \\
\text { Chromosomes } \\
(\text { No })\end{array}$ & $\begin{array}{l}\text { Frequency } \\
(\%)\end{array}$ & Mutation & Nucleotide change & Effect on coding sequence & Reference \\
\hline $3-10$ & $7 / 40$ & 18 & large deletion & & exons 3-10 deleted & 6 \\
\hline 7 & $2 / 40$ & 5 & $\mathrm{I} 133 \mathrm{~F}$ & $\underline{\mathrm{ATC}} \rightarrow \underline{\mathrm{T} G A}$ at 736 & Ile $\rightarrow$ Phe at 133 & This paper \\
\hline 7 & $21 / 40$ & 52 & W138X & $\overline{\mathrm{T}} \mathrm{GG} \rightarrow \overline{\mathrm{T}} \mathrm{GA}$ at 753 & Trp $\rightarrow$ Stop at 138 & 6 \\
\hline 8 & $2 / 40$ & 5 & L158P & $\mathrm{CTG} \rightarrow \mathrm{CCG}$ at 812 & Leu $\rightarrow$ Pro at 158 & This paper \\
\hline 10 & $4 / 40$ & 10 & nt1035(insC) & insert $\mathrm{C}$ after 1035 & frameshift at 233, stop at 295 & 7 \\
\hline
\end{tabular}

microsatellites were amplified and electrophoresed on $6 \%$ Long Ranger (JT Baker, Phillipsburg, NJ, USA) polyacrylamide gels. Gels were blotted on to Whatman 3MM paper and autoradiographs were exposed for 1 to $4 \mathrm{~h}$. After alleles were assigned, haplotyping of cystinosis and non-cystinosis chromosomes in each family was undertaken. To differentiate between the large and small deletions, markers AA313583 and T85505 were amplified as described by Shotelersuk et $a .^{7}$

\section{SSCP Analysis}

Exons 3-12 of CTNS were screened by SSCP using the primers described by Town et al, ${ }^{6}$ except for exon 7 amplification where the primers 5'-TCATGATCACCTGAGGG-3' and 5'-CCGAGGATACGCTTTCT-3' were used, and exon 3 where the primers 5'-CATTTCTCTACGAGCTTC-3' and 5'-AATCGAGAAACATGATAAGG-3' were used, with annealing temperatures of $55^{\circ} \mathrm{C}$ and $60^{\circ} \mathrm{C}$, respectively. Following amplification of each exon, the amplification products were combined with urea/formamide loading dye, denatured at $92^{\circ} \mathrm{C}$, and electrophoresed on PhastGels (Pharmacia, Baie d'Urfé, Quebec, Canada) for 55-170vh. Bands were visualized by silver staining.

\section{DNA Sequencing}

Exon amplification was performed as described above, and the resulting products were purified using a QIAquick PCR Purification kit (Qiagen, Mississauga, ON, Canada). Sequences were determined using a Dye Terminator Cycle Sequencing Core kit with AmpliTaq DNA Polymerase, FS (Perkin Elmer, Mississauga, ON, Canada) and an ABI 373A Automated Sequencer.

\section{Results}

A failure of amplification of D17S829 (Figure 1A, lane 8) and/or aberrant inheritance pattern in several families (Figure 1A), suggested that a deletion containing this microsatellite was present on some cystinosis chromosomes. Amplification of individual exons indicated that this deletion included exons 3-10 of CTNS (data not shown), as described by Town et al. ${ }^{6}$ Also, failure of amplification of markers AA313583 and T85505 in patient10, who is homozygous for the deletion (data not shown), indicated that the large deletion rather than the small deletion ${ }^{6,7}$ is present in this individual.

A single strand conformational polymorphism (SSCP) was detected in exon 10 on four chromosomes present in three families. The observed SSCP band shift (Figure 2A and B) results from the insertion of a single $\mathrm{C}$ after base 1035 (Figure 2C) causing a frameshift, disrupting the normal translation of the gene and ultimately leading to a premature stop at codon 295 (Table 1).

Two novel CTNS mutations were identified by direct sequencing of exons 7 and 8 (data not shown). Sequencing of exon 7 revealed an A-- - $>\mathrm{T}$ at base 736 in two individuals, resulting in the substitution of a phenylalanine for an isoleucine at residue 133 (Table 1). An exon $8 \mathrm{C}---->\mathrm{T}$ mutation at base 812 was found on two chromosomes (Table 1 ) resulting in the substitution of a proline for a leucine in the second putative transmembrane domain ${ }^{6}$ of the cystinosin protein.

An exon 7 mutation (Figure 3) was found on 21 of the 40 chromosomes studied. Sequencing of this exon (Figure 3C) in patients homozygous for this exon 7 mutation (family 14, Figure 3B, right 4 lanes) demonstrated that the mutation which caused the observed SSCP (Figure 3A and B) is a $\mathrm{G}$ to A substitution at base 753, resulting in a stop at codon 138 (Table 1 ). This same mutation (W138X) was detected in two Irish families, but not among French or other continental European cystinosis patients. ${ }^{6}$ Also, it was detected in 14 American patients of German, French, British, Scandinavian and Romanian origins. ${ }^{7}$

In order to determine whether the W138X mutation in our French Canadian cystinotic population was of Irish derivation, we compared the French Canadian haplotypes with those of the Irish patients previously shown ${ }^{6}$ to harbour this mutation. We have determined the haplotype of cystinosis chromosome at $17 \mathrm{p} 13$ from 20 patients of French Canadian origin (Figure 4A) and two Irish patients (Figure 4B), using polymorphic microsatellite repeat markers spanning a roughly $7 \mathrm{cM}$ region. Both of the Irish W138X chromosomes have the 

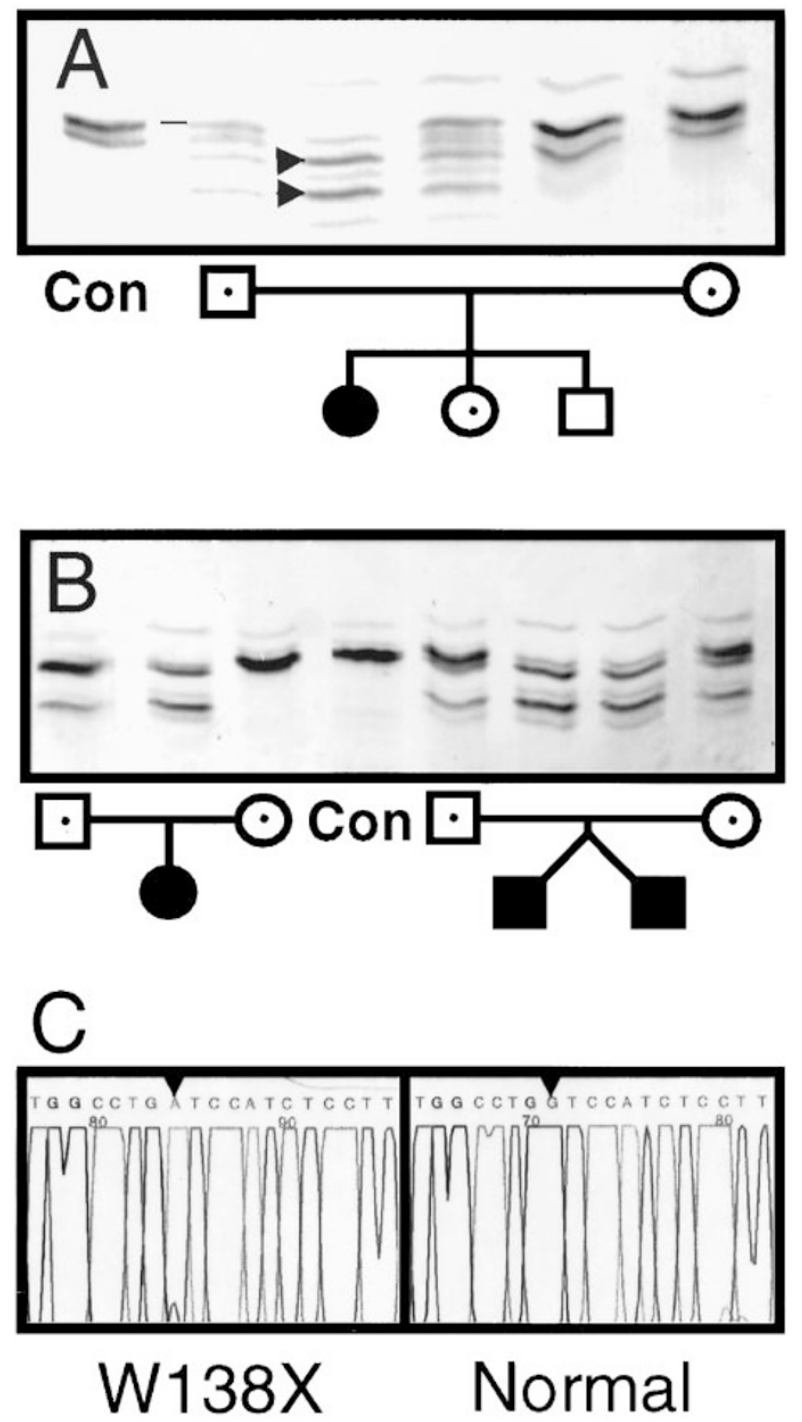

Figure 3 Detection of small mutations in exon 7 of CTNS by SSCP and sequence analysis. 'Con' indicates control DNA. A SSCP of exon 7 in family 17. An exon 7 mutation causes a bandshift (indicated by arrowheads). The proband appears homozygous for an exon 7 mutation, but has inherited the large deletion from her mother, who shows a normal exon 7 SSCP pattern. The sister is an unaffected carrier of the exon 7 mutation, whereas the brother carries neither mutation. B SSCP of exon 7 in families 7 (first 3 lanes) 14 (last 4 lanes). Family 7: the proband appears homozygous for the exon 7 mutation since she inherited the exon 7 mutation from her father and the large deletion from her mother (see Figure $3 A$ ). Family 14: the probands are dizygotic twins and have inherited exon 7 mutations from their mother and father. $\mathbf{C}$ Identification of W138X as the exon 7 mutation by sequencing. Partial sequence of exon 7 , showing a $G$ to $A$ substitution, which results in a stop at codon 138 of CTNS. The proband (left) of family 17 appears homozygous for the W138X mutation, whilst the mother (right), who carries a deletion of exons 3-10 of CTNS, appears normal. same D17S829 allele as all the French Canadian W138X chromosomes. Additionally, the conservation of the haplotype, although not complete, extends to the markers flanking D17S829, lending support to the concept that the French Canadian W138X mutation originated in Ireland.

\section{Discussion}

We have identified causative mutations in the CTNS gene on $36(90 \%)$ of the chromosomes studied. Five CTNS mutations, including two which are novel, have been identified in our study population. Three of these mutations are predicted to cause major disruptions of the CTNS gene, one involving a deletion of most of the gene, the other two causing premature termination of translation. The fourth mutation is predicted to cause the substitution of a proline for a leucine at amino acid residue 158 within the second putative transmembrane domain of the cystinosin protein. In this regard, it is worth noting that all previously described CTNS missense mutations ${ }^{6,7}$ occur within, or one residue away from, a transmembrane domain. It is also present in a yeast transmembrane protein which shares $64 \%$ similarity with cystinosin, whilst a similar amino acid, isoleucine, is present in the same position in a C. elegans protein which is $66 \%$ similar to cystinosin. ${ }^{6}$ The replacement of the conserved leucine residue with the fixed amino bond angle found in proline may result in a loss of transmembrane transport function. The I133F mutation may also cause a major disruption of cystinosin function since it occurs in the first transmembrane domain and involves the replacement of a relatively small side chain with a bulky aromatic ring. The I133F and L158P mutations each accounted for approximately $5 \%$ of the cystinosis chromosomes reported here (Table 1). These mutations were not detected in European ${ }^{6}$ or American ${ }^{7}$ cystinosis populations and may represent recent mutations.

Town et $a l^{6}$ have described CTNS mutations in cystinosis patients of various ethnic origins gathered in London and Paris. The most common mutation in this study was a large deletion encompassing exons 3 to 10 of the CTNS gene; in fact, 22 of the 70 subjects studied were found to be homozygous for this deletion. This deletion was also the most common mutation in a second study which involved 108 American cystinotics, $44 \%$ of whom were homozygous for this mutation. ${ }^{7}$ Our study of 20 cystinosis patients revealed only one homozygote, and five who are heterozygotes, for the 


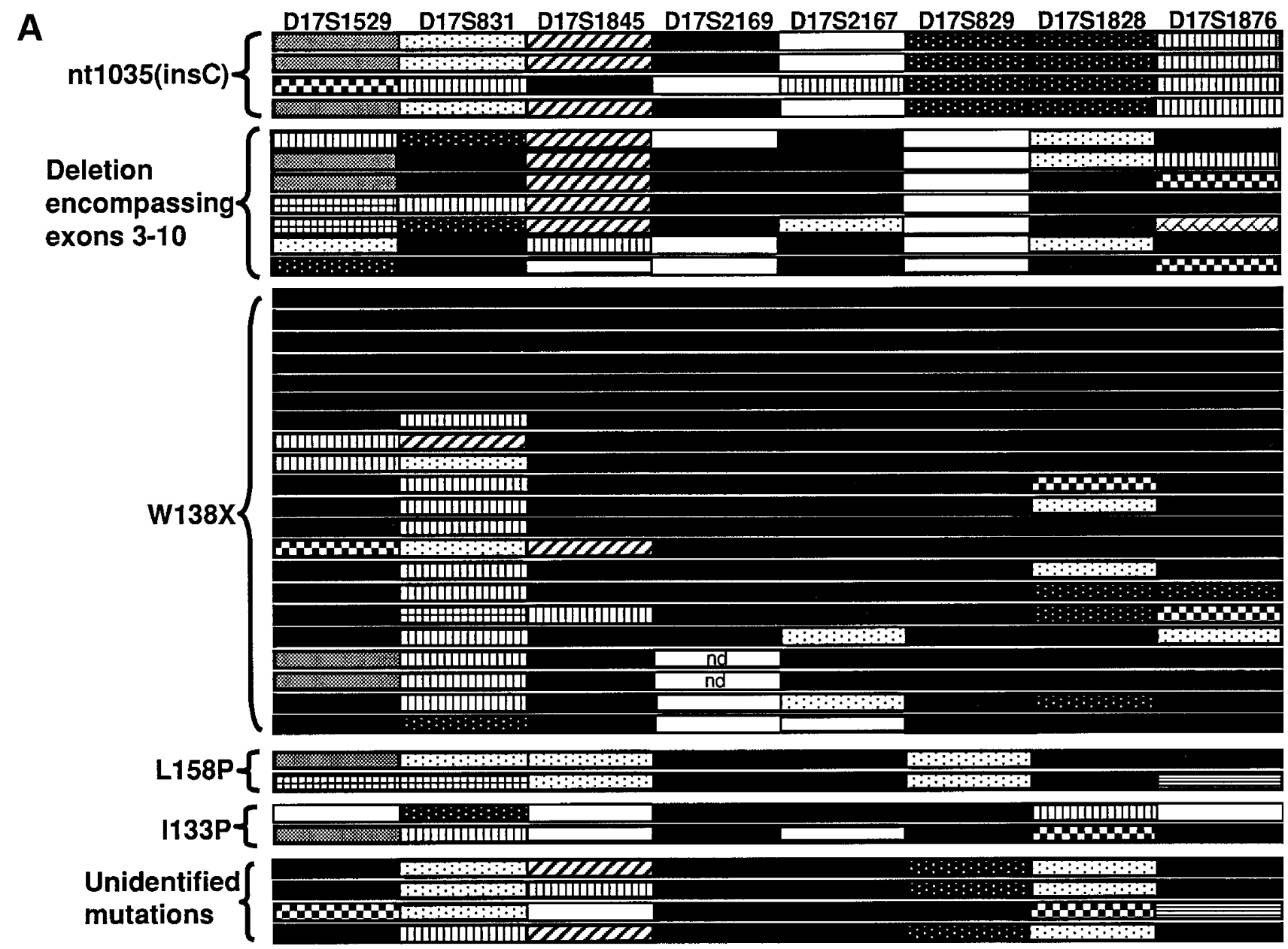

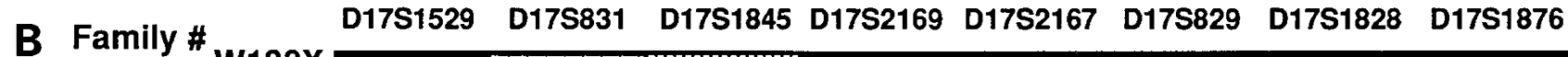 L26 ${ }^{\text {W } 138 X}$ del

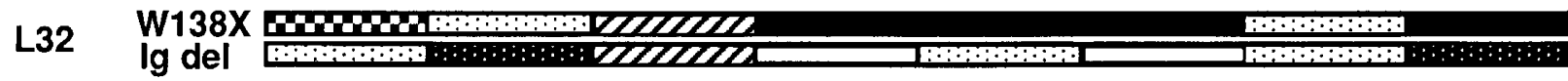

Figure 4 Haplotype analysis of cystinosis chromosomes. Each bar represents the portion of an individual chromosome 17 from D17S1529 to D17S1876. Maternal and paternal chromosomes from $\mathbf{A}$ each of 20 French Canadian and $\mathbf{B}$ Irish cystinosis patients are shown. For patient L32, all alleles are interchangeable between chromosomes since no parental samples were available. Both Irish patients were compound heterozygotes with the W138X and large deletion mutations (Margaret Town, personal communication 1998). The CTNS mutation on each chromosome is indicated to the left. Each allele of each microsatellite repeat marker is represented by a specific pattern; ' $n d$ ' indicates that the allele was not determined.

deletion of exons 3 to 10 of CTNS, reflecting a much lower frequency of the deletion allele in our French Canadian population than in either group previously studied, assuming a random assortment. Due to inaccessibility of some parental DNA samples, however, there may be as many as three undetected chromosomes carrying the deletion, bringing the maximum number of deleted chromosomes to ten, still well below the European allele frequency of 50-60\% suggested by the Town et $a l^{6}$ data.

We have analysed the haplotype at 17 p13 of 40 chromosomes originating from 20 French Canadian cystinosis patients. It is probable, from consideration of these haplotypes (Figure 4A), that all of the deletions found in the French Canadians studied here are identical. Markers which flank the deleted region vary 
between only two alleles, suggesting that this region of these chromosomes is conserved, with markers further away from D17S829 exhibiting more variability.

In contrast to the French, British and American cystinosis populations, the most frequently observed mutation in French Canadian cystinotics is the previously identified $\mathrm{W} 138 \mathrm{X}$ point mutation. In considering the origin of this CTNS mutation, one would typically look to France, since Quebec was founded by successive waves of French immigrants from 1608 to $1763 .{ }^{13}$ Surprisingly, in the original report, the common W138X mutation was not found in any patients from Paris; rather, the two patients exhibiting this mutation were from Ireland. ${ }^{6}$ Identity of haplotypes between chromosomes from French Canadian and Irish cystinotic individuals lends further credibility to the notion that W138X has Irish rather than French origins. Possible explanations for the presence of this mutation in French Canada include the massive emigration of the Irish to Canada, during the Great Potato Famine of 1846-1851. ${ }^{14,15}$ Also to be considered are the estimated 400000 Irish who landed in British North America, many in Quebec, before the Potato Famine. ${ }^{16}$ Indeed, by 1871 over 120000 Quebecers, representing $10-15 \%$ of the population, were of Irish origin.

Natural rapid expansion of the population, combined with the relative isolation of the population from a linguistic standpoint has contributed to the founder effect noted in the distribution of several genetic diseases in the French Canadian population of Quebec. $^{10,11,17-20}$ Our haplotype analysis, covering eight microsatellite repeats at chromosome $17 \mathrm{p} 13$, revealed some evidence for common patterns in all five cystinosis mutations, suggestive of a number of founding chromosomes. More compelling evidence for such effects is seen in the complete disequilibrium observed between D17S829 alleles for each of the five different mutations (Figure 4). Our data suggest that there are several founding cystinosis mutations in the French Canadian population, with origins both in France and Ireland, with the 'Celtic' cystinosis mutation having made the most significant contribution to cystinosis in the present-day population of French Canada. We are aware of one previous example of Celtic disease chromosomes in Quebec: phenylketonuria chromosomes harbouring 'Celtic' haplotypes have been found in the Saguenay-Lac St Jean and Charlevoix regions of Quebec. ${ }^{21}$

Finally, with the cloning of the CTNS gene has come a better understanding of the molecular basis of nephropathic cystinosis. For diagnostic purposes, it is important to have both a knowledge of the mutations in a particular population and a high rate of mutation detection. Here we describe five CTNS mutations which account for about $90 \%$ of cystinosis alleles in French Canadians. The majority of these mutant chromosomes are detectable by SSCP, a rapid assay, permitting molecular diagnosis of this tragic disease. Additionally, all of the point mutations described here are detectable by RFLP (data not shown). The high degree of ascertainment of CTNS mutations will be especially valuable in areas of French Canada such as Saguenay-Lac St Jean and Charlevoix where the incidence of nephropathic cystinosis is estimated at one in 6000 births. $^{8}$

\section{Acknowledgements}

We are indebted to the families involved in this study. The work was supported by grants from the Kidney Foundation of Canada and the Research Institute of the Children's Hospital of Eastern Ontario, and a Medical Research Council of Canada grant to Dr Nicole Begin-Heick. The authors wish to thank Anne Besner-Johnston and Christine McRoberts for technical assistance. Also, Dr Guy Mongeau at Hôpital Ste Justine was helpful in the collection of patient samples.

\section{References}

1 Gahl WA, Bachan N, Trietze F, Bernardi I, Schulman JD: Cystine transport is defective in isolated leukocyte lysosomes from patients with cystinosis. Science 1982a; 217: 1263-1265.

2 Gahl WA, Treitze F, Bachan N, Steinberg R, Schulman JD: Defective cystine exodus from isolated lysosomal-rich fractions cystinotic leukocytes. J Biol Chem 1982b; 257: 9570-9575.

3 Gahl WA, Schneider JA, Aula PP: Lysosomal transport disorders: Cystinosis and sialic acid disorders. In: Scriver CR, Beaudet AL, Sly WS, Valle D (eds): The Metabolic Basis of Inherited Disease. McGraw Hill: New York, 1995,pp 3763-3797.

4 Jean G, Fuchshuber A, Town MM et al: High-resolution mapping of the gene for cystinosis, using combined biochemical and linkage analysis. Am J Hum Genet 1996; 58: $535-543$.

5 McDowell G, Isogai T, Tanigami A et al: Fine mapping of the cystinosis gene using an integrated genetic and physical map of a region within human chromosome band 17p13. Biochem Mol Med 1996; 58: 135-141.

6 Town M, Jean G, Cherqui S et al: A novel gene encoding an integral membrane protein is mutated in nephropathic cystinosis. Nat Genet 1998; 18: 319-324.

7 Shotelersuk V, Larson D, Anikster Y et al: CTNS mutations in an American-based population of cystinosis patients. Am J Hum Genet 1998; 63: 1352-1362. 
8 De Braekeleer M: Hereditary disorders in Saguenay-LacSt-Jean (Quebec, Canada). Hum Hered 1991; 41: 141-146.

9 Gahl WA, Thoene JG, Schneiter JA, O'Regan S, KaiserKupfer MI, Kuwabara T: Cystinosis: Progress in a prototypic disease. Ann Intern Med 1988; 109: 557-569.

10 De Braekeleer M, Dionne C, Gagne C et al: Founder effect in familial hyperchylomicronemia among French Canadians of Quebec. Hum Hered 1991; 41: 168-173.

11 Labuda M, Labuda D, Korab-Laskowska M et al: Linkage disequilibrium analysis in young populations: pseudovitamin D-deficiency rickets and the founder effect in French Canadians. Am J Hum Genet 1996; 59: 633-643.

12 McLaine P, Orrbine E: The Canadian Pediatric Kidney Disease Research Centre. Ann Roy Coll Phys Surg Canada 1989; 22: 531-532.

13 Harris RC, Matthews G: Historical Atlas of Canada. I. From the Beginning to 1800 . University of Toronto Press: Toronto, 1987.

14 O'Driscoll R, Reynolds L: The Untold Story: the Irish in Canada. I. Celtic Arts of Canada: Toronto, 1988.

15 O'Gallagher M, Dompierre RM: Eyewitness: Grosse Isle 1847. Livres Carraig Books: Sainte Foy, Quebec, 1995.
16 Wilson DA: The Irish in Canada. The Canadian Historical Association: Ottawa, 1989.

17 DeBraekeleer M, Larocelle J: Population genetics of vitamin D-dependent rickets in northeastern Quebec. Ann Hum Genet 1991; 55: 283-290.

18 Hobbs HH, Brown MS, Russel DW, Davignon J, Goldstein JL: Deletion in the gene for the low-density lipoprotein receptor in a majority of French Canadians with familial hypercholesteremia. N Engl J Med 1987; 317: 734-737.

19 De Braekeleer M, Daigneault J, Allard C, Simard F, Aubin G: Genealogy and geographical distribution of CFTR mutations in Saguenay-Lac-Saint-Jean (Quebec, Canada). Ann Hum Biol 1996; 23: 345-352.

20 MacKenzie AE, MacLeod HL, Hunter AG, Korneluk RG: Linkage analysis of the apolipoprotein $\mathrm{C} 2$ gene and myotonic dystrophy on human chromosome 19 reveals linkage disequilibrium in a French-Canadian population. Am J Hum Genet 1989; 44: 140-147.

21 Treacy E, Byck S, Clow C, Scriver CR: 'Celtic' phenylketonuria chromosomes found? Evidence in two regions of Quebec Province. Eur J Hum Genet 1993; 1: 220-228. 